\title{
Endothelial von Willebrand Factor Release Due to eNOS Deficiency Predisposes to Thrombotic Microangiopathy in Mouse Aging Kidney
}

Takahiro Nakayama, ${ }^{\text {† }}$ Waichi Sato, ${ }^{*}$ Ashio Yoshimura, ${ }^{\ddagger}$ Li Zhang, ${ }^{\S}$ Tomoki Kosugi, ${ }^{\star \dagger}$ Martha Campbell-Thompson, ${ }^{\S}$ Hideto Kojima, ${ }^{\text {"I }}$ Byron P. Croker, ${ }^{\S}$ and Takahiko Nakagawa* ${ }^{\dagger}$

From the Division of Nephrology," and the Department of Pathology-Immunology-Laboratory Medicine, ${ }^{\circledR}$ University of Florida, Gainesville, Florida; the Division of Renal Disease and Hypertension, ${ }^{\dagger}$ University of Colorado Denver, Aurora, Colorado; the Division of Nephrology, ${ }^{\ddagger}$ Showa University Fujigaoka Hospital, Kanagawa, Japan; and the Division of Molecular Genetics in Medicine, "ा Shiga University of Medical Science, Otsu, Shiga, Japan

Endothelial dysfunction is critical in the decline of renal function with. By using endothelial nitric oxide synthase knockout (eNOSKO) mice, we tested the hypothesis that a lack of endothelial nitric oxide synthase accelerates renal injury in the aging kidney. In contrast to control mice and young eNOSKO mice, aging eNOSKO mice showed greater renal injury and in particular developed a thrombotic microangiopathy, with mesangiolysis, endothelial swelling, endothelial cell loss, double-contour appearance of glomerular basement membrane (GBM), and thrombus formation. Thrombi, which were composed of fibrin, platelets, and von Willebrand factor (vWF), were identified predominantly in glomerular capillaries and rarely in arterioles, but not in larger vessels. In the tubulointerstitium, tubular degeneration and macrophage infiltration were also prominent in aging eNOSKO mice. Intraluminal vWF deposition was accompanied with thrombus formation, whereas mesangial deposition of VWF was associated with mesangial matrix expansion. Furthermore, the mesangial VWF deposition was detectable in young eNOSKO mice in which severe glomerular injury had not yet developed. Finally, a higher level of serum P-selectin in eNOSKO mice was consistent with the vWF behavior and suggested exocytosis of the WeibelPalade body by the endothelium. In conclusion, a lack of endothelial nitric oxide synthase resulted in the development of glomerular thrombotic microangiopathy. A lack of nitric oxide likely contributed to the release of $\mathrm{VWF}$, leading to thrombus formation in this model. (Am J Pathol 2010, 176:2198-2208; DOI: 10.2353/ajpath.2010.090316)

Preservation of endothelial function is important in maintaining normal kidney function. A key role of the endothelium is to produce nitric oxide (NO), which is catalyzed by endothelial NO synthase (eNOS) and induce a vasodilator that helps maintain endothelial cell integrity with antithrombotic properties. In fact, Huang et al ${ }^{1}$ demonstrated that genetic deletion of eNOS resulted in hypertension due to endothelial dysfunction. Forbes et $\mathrm{al}^{2}$ recently demonstrated that target deletion of eNOS results in some congenital renal abnormalities, including glomerular hypoplasia and tubular cell death, but the injuries are focal and therefore the renal anatomy of endothelial nitric oxide synthase knockout (eNOSKO) mice is largely normal. ${ }^{3,4}$ Compatibly, we also reported that renal function is well preserved at 5 months of age in the eNOSKO mouse. ${ }^{5,6}$ Despite normal appearance, a lack of eNOS seems to increase the susceptibility to renal disease. For instance, we and others demonstrated that a lack of eNOS gene accelerates the progression of renal injury in the diseased kidney, including diabetic nephropathy, ${ }^{5}$ remnant kidney, ${ }^{6-8}$ and anti-GBMglomerulonephritis. ${ }^{3}$ These studies indicate the protective role of eNOS in the diseased kidney.

Aging is associated with a progressive decline in renal function along with glomerular and tubulointerstitial injuries. ${ }^{9,10}$ An impairment of endothelial function is considered to be a critical risk factor for the progression of renal injury in the aging kidney. ${ }^{9}$ Recent studies have also documented a protective role of NO on endothelial se-

Supported by the Juvenile Diabetes Research Foundation (JDRF), NIH grant DK-52121, and by generous funds from Gatorade.

Accepted for publication January 13, 2010

Address reprint requests to Takahiko Nakagawa, M.D., Ph.D., Division of Renal disease and Hypertension, University of Colorado Denver, Mail Stop C281, Aurora, CO 80045. E-mail: takahiko.nakagawa@ucdenver.edu. 
nescence. ${ }^{11}$ Nevertheless, to date there is no direct evidence of the role of endothelial dysfunction in aging-associated renal disease. We therefore tested the hypothesis that a lack of NO could accelerate renal aging-associated renal disease.

\section{Materials and Methods}

\section{Animal Models and Measurement of Blood Pressure}

Two-month-old C57BL/6J male mice (C57) and C57BL/ 6J-Nos3tmlUnc (eNOS-/-) male mice (eNOSKO) were purchased from Jackson Laboratory (Bar Harbor, ME). These mice were housed in the vivarium at the University of Florida for 11 months. Systolic blood pressure was measured by a tail-cuff sphygmomanometer (Visitech BP2000; Visitech Systems, Apex, NC). Four mice were sacrificed to obtain kidney, blood, and urine at the age of 2 months after blood pressure measurement in each group. Eleven months later, the other seven mice in each group were sacrificed. All experiments were approved by the Animal Care and Use Committee of the University of Florida.

\section{Renal Histology}

Renal tissue was fixed in Fekete's fixative, embedded in paraffin blocks, and cut into $2-\mu \mathrm{m}$ sections. Periodic acid-Schiff staining was used for morphological analysis. In immunohistochemistry, a polyclonal rabbit anti-mouse fibrinogen antiserum (Innovative Research, Novi, MI) was used for fibrin deposition; a rat anti-mouse CD34 antibody (BD Pharmingen, San Jose, CA) for endothelial cells; a polyclonal goat anti-mouse collagen III antibody (Southern Biotech, Birmingham, AL) for interstitial collagen III deposition; a polyclonal rabbit anti-mouse collagen IV antibody (Chemicon International, Temecula, CA) and a polyclonal rabbit anti-mouse fibronectin antibody (Sigma, St. Louis, MO) for mesangial matrix; a polyclonal rat anti-mouse F4/80 antibody (Serotec, Raleigh, NC) for macrophage; a polyclonal rabbit anti-mouse von Willebrand factor (VWF) antibody (Dako, Carpinteria, CA) for von Willebrand factor; a polyclonal rabbit anti-mouse WT-1 antibody (Santa Cruz, Santa Cruz, CA) for podocyte; and a polyclonal rabbit anti-mouse desmin antibody (Abcam Inc, MA) for desmin expression. Color was developed by using diaminobenzidine as a chromogen. For immunofluorescence, tissues were embedded in optimal cutting temperature compound, frozen in liquid nitrogen, and stored at $-80^{\circ} \mathrm{C}$. Four-micron sections were fixed with $10 \%$ neutral buffered formalin, applied with rat antimouse CD34 and rabbit anti-mouse vWF antibody, followed by incubation with fluorescein isothiocyanate conjugated goat anti rat IgG and Texas Red conjugated goat anti-rabbit IgG. All sections were covered with Vectashield with 4,6-diamidino-2-phenylindole (Vector Laboratories, Burlingame, CA) and examined by fluorescence microscopy. For electron microscopic analysis, kidneys were fixed in formalin, embedded in epoxy resin, and stained with uranyl acetate and lead citrate.

\section{Quantification of Morphology}

All slides were examined in a blinded manner. All glomeruli (>50 glomerular cross sections per biopsy) were examined. After tubulointerstitial lesions (with sparing of glomeruli) of the whole renal cortical area in the axial plane was scanned with the AxioVision image analyzer (Carl Zeiss, Thornwood, NY), 10 to 20 fields, which could cover whole renal cortex in axial section, were examined per biopsy. Glomerulosclerosis, mesangiolysis, and glomerular basement membrane (GBM) double contour were assessed by the ratio of injured glomerular number to total glomerular number. ${ }^{5}$ By using AxioVision image analyzer (Carl ZEISS, Germany), the total dimension of glomerulus was determined by tracing the outline of glomerular tuft. The extent of the mesangial matrix (defined as mesangial area) was determined by assessing the periodic acid-Schiff-stained area (red color). The \% mesangial area was calculated as the mesangial area $\left(\mu \mathrm{m}^{2}\right)$ divided by the total area of the glomerular tuft. To examine glomerular capillary, both absolute capillary number per a glomerulus and capillary density (as defined as the number of capillaries per glomerular area) was determined on periodic acid-Schiff staining. To quantify glomerular lesions, we measured the positive immunostained area in each glomerular cross section for collagen IV, fibronectin, vWF, CD34, and fibrinogen as an overall \% positive area of the glomerular tuft as measured using computer image analysis. The \% positive area was determined as positive area $\left(\mu \mathrm{m}^{2}\right)$ divided by total area for each glomerular tuft. F4/80-positive cells were simply counted in each glomerular cross section. The podocyte number (determined by total WT1 positive cells per glomerular cross section) was factored for total glomerular area (measured as the tuft area by computer image analysis). While desmin was expressed in mesangium, we examined the number of glomeruli only with any degree of podocyte desmin expression, which was divided by total number of glomeruli to assess \% positive glomeruli with podocyte desmin. Fibrin deposits/thrombi were defined as the accumulation of dark eosinophilic fibrillar or amorphous material within the glomerular capillaries in H\&E staining as described previously, ${ }^{12}$ and were authenticated by fibrin staining. Similarly, vascular vWF in arcuate artery, interlobular artery, and arteriole, respectively was evaluated as percent positive area in vascular cross-sections. To assess peritubular capillary, $\%$ positive signal for CD34 in peritubular area was determined, and then divided by total number of tubules in that area. ${ }^{9}$ A tubule surrounded by a tubular basement membrane was used to count tubular number while majority of tubules examined were in cross section since we cut kidney using a transverse plane. In whole renal cortex, the \% positive area for collagen III, and the number of F4/80 positive cells (per $0.25 \mathrm{~mm}^{2}$ ) were determined to assess interstitial injury. 


\section{Biochemical Measurements and Serum Assays for P-Selectin}

Creatinine was measured by using a specific assay (Bio Quant, Dan Diego, CA). Urinary albumin concentration was determined by a rat albumin enzyme-linked immunosorbent assay kit (Albuwell M; Exocell, Philadelphia, PA) and the albumin-to-creatinine ratio was calculated. Serum soluble P-selectin concentration was quantified by a mouse P-selectin enzyme-linked immunosorbent assay kit (Quantikine; R\&D Systems, Minneapolis, MN).

\section{Urinary NO Assay}

To examine the renal $\mathrm{NO}$, the concentration of urinary nitrate $\left(\mathrm{NO}_{3}^{-}\right)$and nitrite $\left(\mathrm{NO}_{2}^{-}\right)$were determined by Nitric Oxide Analyzer 280i (SIEVERS, Boulder, CO).

\section{Statistical Analysis}

All statistical analyses were performed by using SPSS 16.0 (Chicago, IL). All data are shown as means \pm SD. The equality of variances was verified by Levene's test and the unpaired $t$-test was used to compare the means of two groups of unpaired measurement. Oneway analysis of variance followed by the Tukey's test was used for three or more groups' comparison. The Pearson correlation coefficient $r$ and the significance probability were calculated to determine the strength of the correlation. Statistical significance was defined as $P<0.05$.

\section{Results}

\section{General Parameters}

As shown in Table 1, blood pressure was significantly elevated in eNOSKO mice at 2 months and 13 months compared with C57BL6 mice. While body weight was identical between two groups at both time points, kidney weight was significantly reduced in eNOSKO mice, as compared with C57BL6 mice at 13 months. Serum creatinine was significantly higher in eNOSKO mice, as compared with C57BL6 mice at the age of 13 months, although it was no different in young mice. Compatibly, urinary albumin excretion was significantly elevated in
eNOSKO mice in 13-month-old mice, as compared with that of C57BL6 mice of the same age.

\section{Renal Histology}

As previously reported, we found congenital glomerular and tubular lesions in focal areas, ${ }^{2}$ whereas the majority of kidney looked normal by routine histology. ${ }^{3,4}$ In this study, histological analysis was confined to regions of the kidney where congenital lesions were absent.

\section{Glomerular Changes in Aging}

Glomerular abnormalities were not detected in eNOSKO mice or C57BL6 mice at 2 months of age (Figure 1, A and B). In contrast, eNOSKO mice developed glomerular hypertrophy mesangiolysis, glomerulosclerosis with hyalinosis of arterioles, and glomerular capillary microaneurysms at 13 months of age, while mild mesangial prominence was shown in wild-type mice (Figure 1, C-H). The vessel walls of capillaries and arterioles were often thickened. Some glomeruli exhibited a double-contour appearance in glomerular basement membrane, due in part to mesangial interposition (Figure $1 \mathrm{H}$ ).

Quantitative analysis confirmed that eNOSKO mice did not display significant glomerular injury at 2 months old. In contrast, a lack of eNOS was associated with significant glomerular hypertrophy, mesangial expansion, mesangiolysis, glomerulosclerosis, and glomerular basement membrane (GBM) double contour in older (age 13 months) mice (Figure 1, I-M).

Electron microscopy confirmed the presence of mesangial expansion and mesangial interposition (Figure 1, N-P) in eNOSKO mice. Capillary obliteration, due mostly to mesangial and endothelial cellular hypertrophy, was also observed.

While increased glomerular collagen IV deposition was observed at 13-months-old in eNOSKO mice (Figure 2A), fibronectin deposition was also increased in glomeruli of eNOSKO mice as early as 2 months and remained elevated at 13 months old (Figure 2B). F4/80 (+) macrophage infiltration in glomeruli of eNOSKO mice was also increased in older (13 months old), but not younger (2 months old) mice (Figure 2C).

Finally, we examined if the eNOSKO mice had evidence for podocyte injury. The number of WT-1 (+) podocytes in eNOSKO mice was significantly decreased in both young and aging eNOSKO mice, as compared with

Table 1. General Characteristics*

\begin{tabular}{|c|c|c|c|c|}
\hline \multirow[b]{2}{*}{ Mice } & \multicolumn{2}{|c|}{ C57BL6 } & \multicolumn{2}{|c|}{ eNOS KO } \\
\hline & $2 \mathrm{mo}$ & $13 \mathrm{mo}$ & $2 \mathrm{mo}$ & $13 \mathrm{mo}$ \\
\hline Body weight (g) & $21.4 \pm 0.7$ & $33.0 \pm 3.5$ & $22.6 \pm 0.4$ & $31.8 \pm 2.6$ \\
\hline Systolic BP (mmHg) & $115 \pm 4$ & $102 \pm 9$ & $128 \pm 3^{\ddagger}$ & $133 \pm 14^{\dagger}$ \\
\hline Kidney weight $\left(\times 10^{-3} \mathrm{~g} / \mathrm{BW}\right)$ & $7.0 \pm 0.2$ & $5.7 \pm 0.4$ & $7.1 \pm 0.8$ & $5.3 \pm 0.7^{\ddagger}$ \\
\hline Serum $\mathrm{Cr}(\mathrm{mg} / \mathrm{dl})$ & $0.11 \pm 0.02$ & $0.13 \pm 0.02$ & $0.12 \pm 0.03$ & $0.17 \pm 0.02^{\ddagger}$ \\
\hline urine $\mathrm{Alb} / \mathrm{Cr}\left(\times 10^{-1}\right)$ & $1.6 \pm 0.5$ & $8.1 \pm 2.4$ & $5.2 \pm 3.7$ & $52.9 \pm 15.2^{\dagger}$ \\
\hline
\end{tabular}

*Data are means $\pm \mathrm{SD}$.

${ }^{\dagger} P<0.01$ versus C57BL6 of the same age.

${ }^{\ddagger} P<0.05$ versus C57BL6 of the same age. 

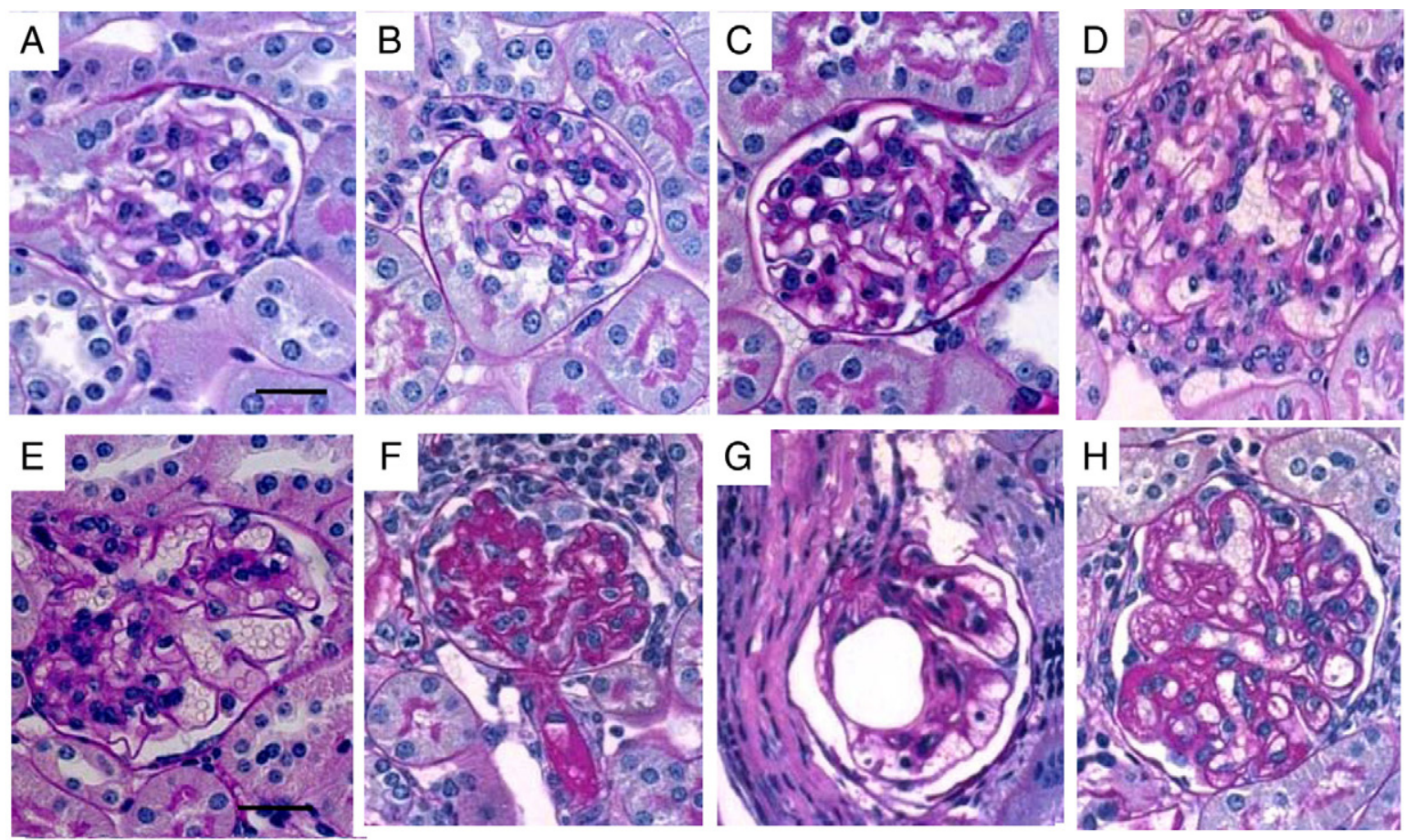

I

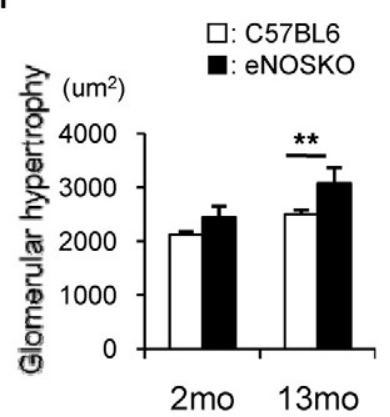

M

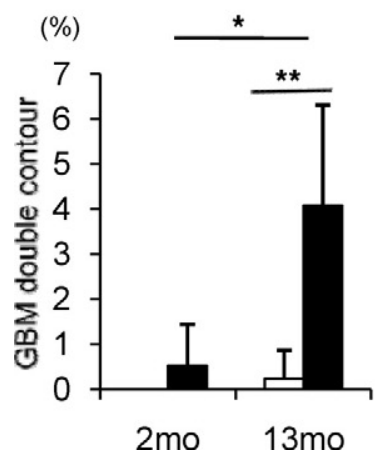

$\mathrm{J}$
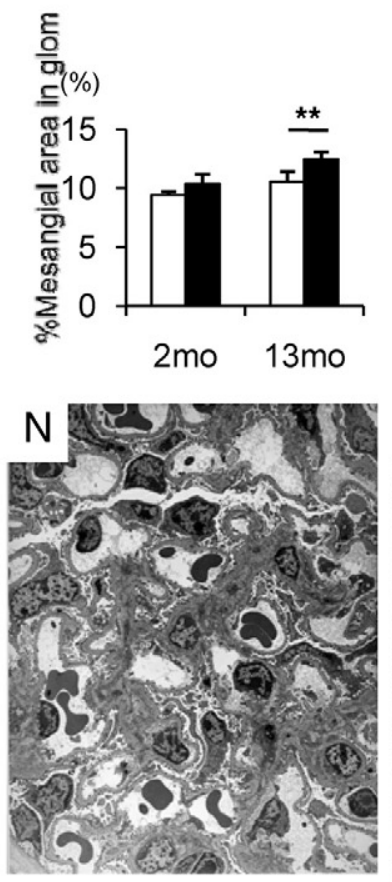

K

(\%)
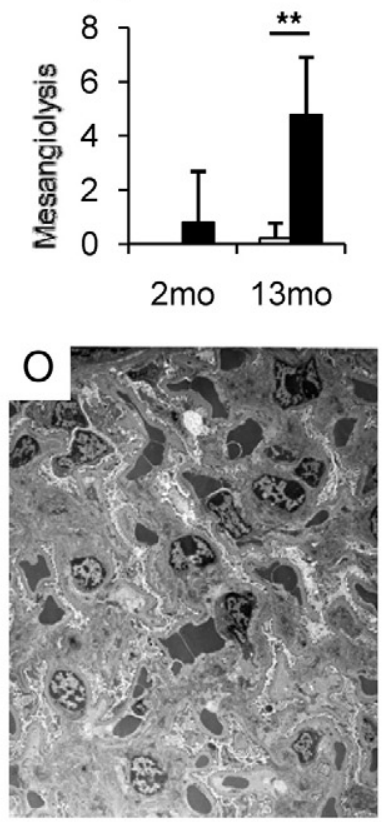

L

(\%)

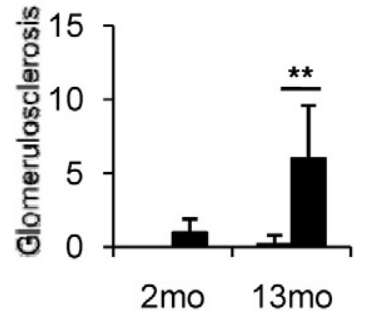

Figure 1. Glomerular changes in aging eNOSKO mice. Glomeruli in wild-type (A) and eNOSKO mice (B) look normal in histological appearance at 2 months of age. Wild-type mice had mild mesangial prominence at 13 months of age as would be expected with aging (C), eNOSKO mice developed glomerular hypertrophy (D), mesangiolysis (E), glomerulosclerosis (F), glomerular capillary microaneurysm (G), and double-contour appearance of glomerular basement membrane (GBM; $\mathbf{H})$, Scale bar $=20 \mu \mathrm{m}$. Quantifications for glomerular hypertrophy $(\mathbf{I})$, mesangial expansion $(\mathbf{J})$, mesangiolysis $(\mathbf{K})$, glomerulosclerosis $(\mathbf{L})$, and double contour $(\mathbf{M})$ are shown. Electron microscopy also demonstrates that compared with wild-type mice $(\mathbf{N}$; original magnification $\times 1500)$, eNOSKO mice exhibit mesangial expansion and obliteration of capillary space due mostly to mesangial and endothelial cellular hypertrophy $(\mathbf{O} ; \times 1500)$. Mesangial interposition and focal duplication of a glomerular capillary loop is also noted (arrow in $\mathbf{P} ; \times 3000$ ). White bar $=$ C57BL6; Black bar $=$ eNOSKO. Data are shown as means \pm SD. ${ }^{*} P<0.05$, ${ }^{* *} P<0.01$.

age-matched wild-type mice (Figure 2, D-H). Aging process likely caused the podocyte loss in both types of mice (Figure 2, D-H). Compatibly, podocyte desmin expression was significantly higher in aging eNOSKO mice compared with wild-type mice, whereas it tended to be also higher in eNOSKO mice at 2 months of age (Figure 2, I-L). Consistent with the light microscopy findings, podocyte injury, as evidenced by foot process fusion, protein phagoly- 


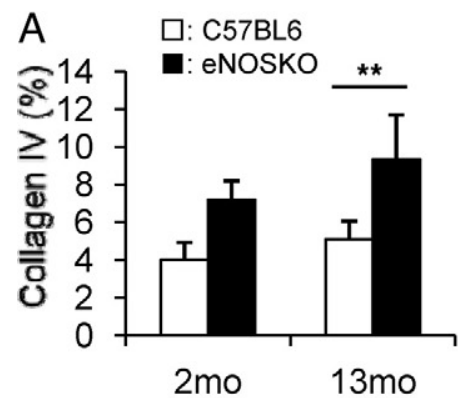

B

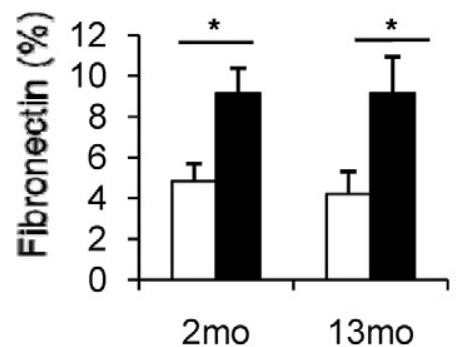

C

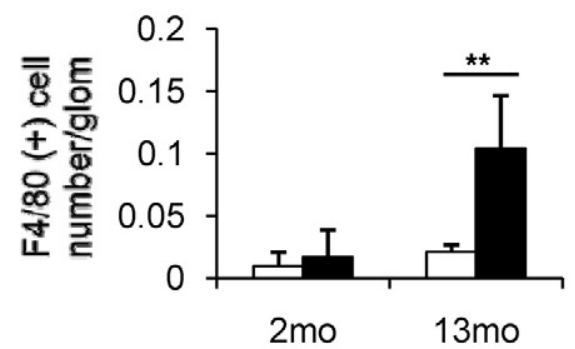

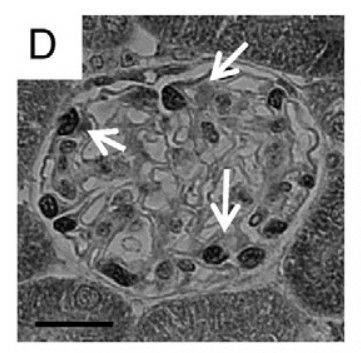
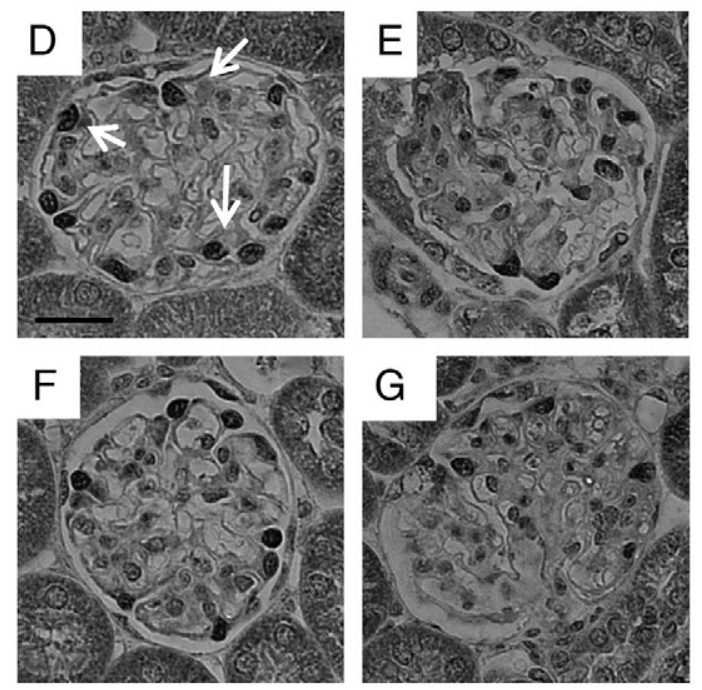

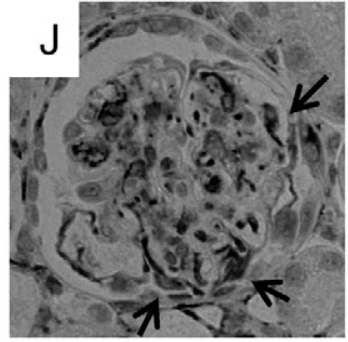

* 6

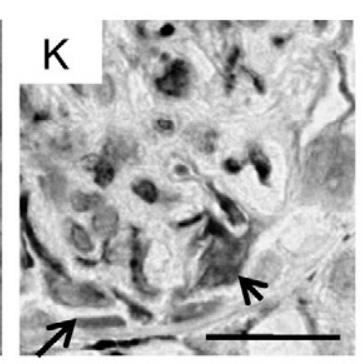

$\mathrm{H}$
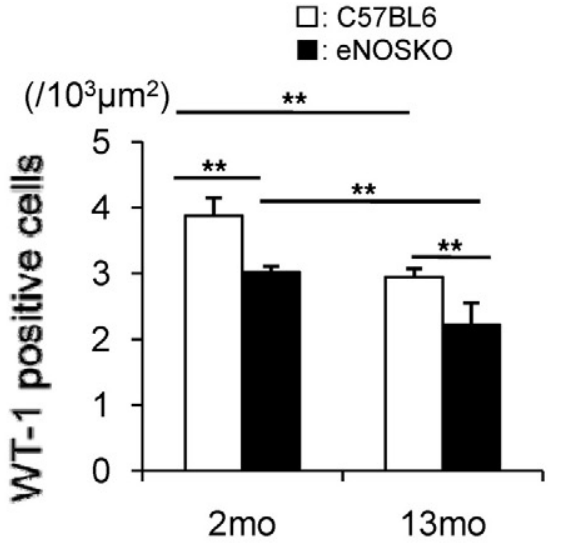

$\mathrm{M}$

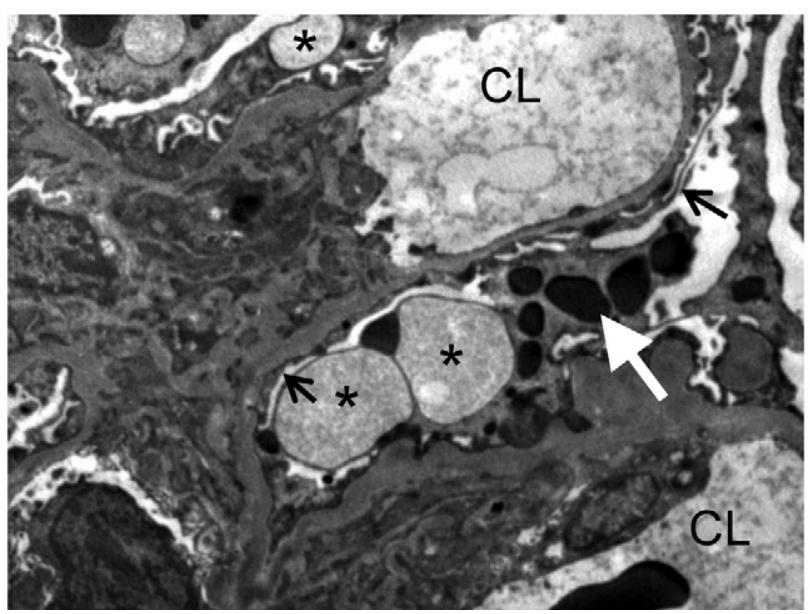

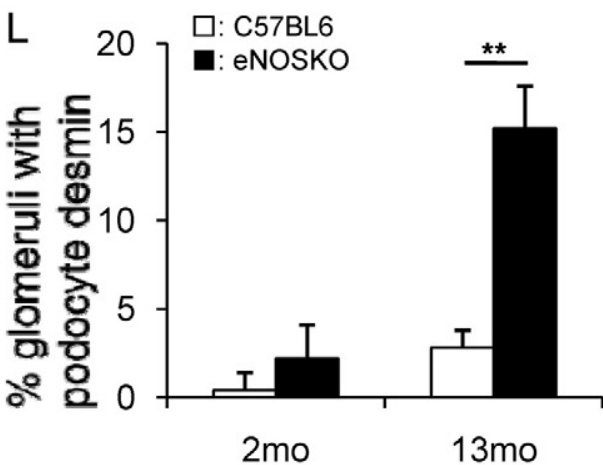

Figure 2. Glomerular disease in eNOSKO mice. \% positive area in glomerulus is shown for glomerular collagen IV deposition (A) and for fibronectin deposition $(\mathbf{B})$ is shownF4/80 $(+)$ macrophage infiltration is significantly higher in eNOSKO mice at 13 months of age (C). Compared with young control mice (D), and young eNOSKO mice (E), WT1 (+) podocytes (arrow) also decrease in number in eNOSKO mice (G), as compared with wild-type mice (F) at 13 months of age. Scale bar = $20 \mathrm{um}$. The number of WT-1 positive cells $/ 10^{3} \mu \mathrm{m}^{2}$ of glomerular area was quantified $(\mathbf{H}) . \%$ glomeruli with desmin expression are shown in (E). Compared with old wild-type mice (I), desmin expression in podocyte (arrow) also increases in eNOSKO mice (J) at 13 months of age. (K) shows higher power view of $(\mathbf{J})$. Scale bar $=20 \mathrm{um}$. The number of glomerulus with desmin expression was divided by total number of glomerulus to calculate \% glomeruli with desmin expression (L). As a feature of podocyte injury, foot process effacement (arrow) and vacuolation (asterisk) and protein phagolysomes (white arrow) in podocyte are also found in addition to mesangial expansion in aging eNOSKO mice $(\mathbf{M} ; \times 3000)$. CL: capillary lumen. White bar $=$ C57BL6; black bar $=$ eNOSKO. Data are shown as means \pm SD. ${ }^{*} P<0.05,{ }^{*} P<<0.01$. 

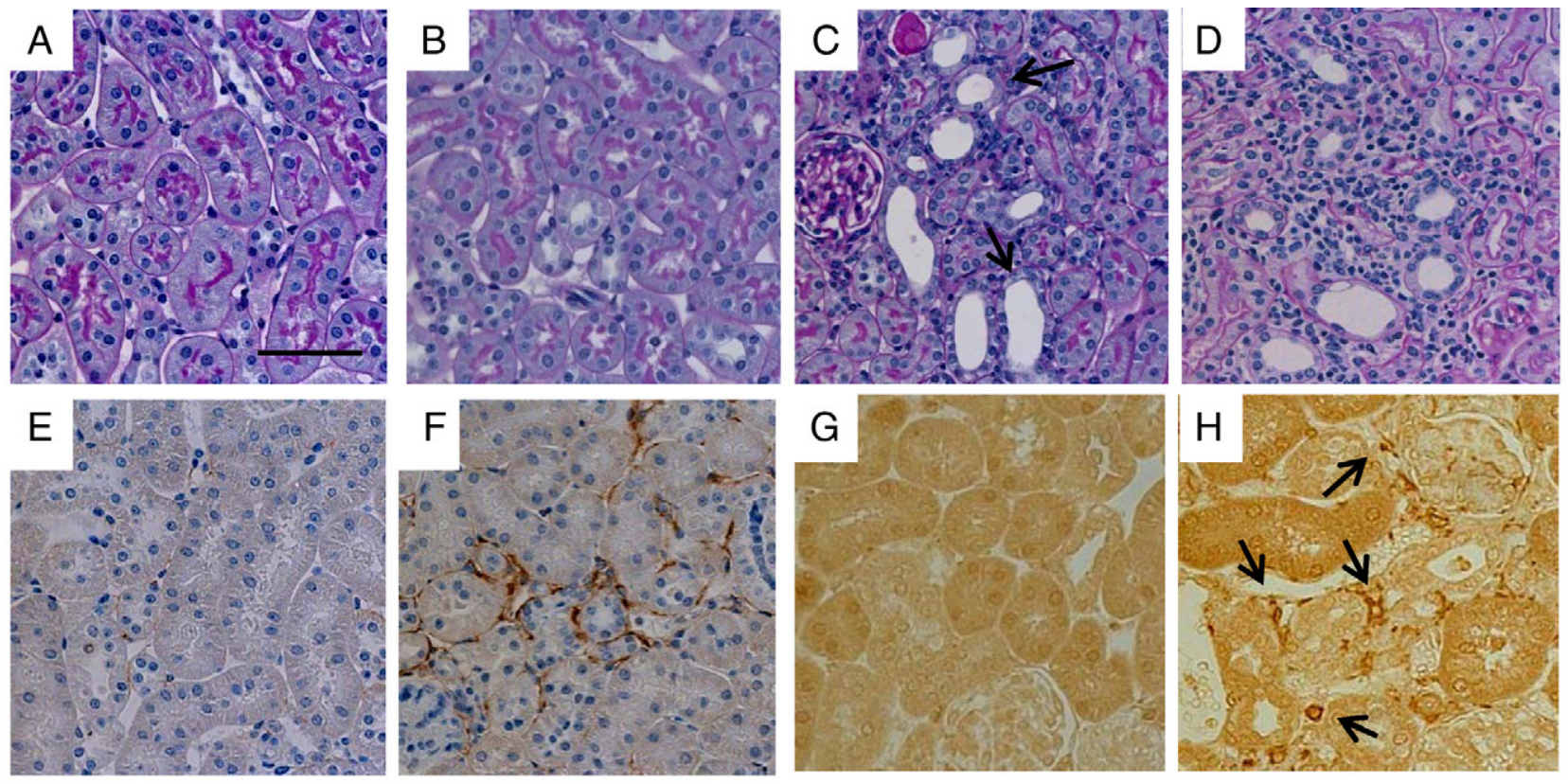

\section{Col III}

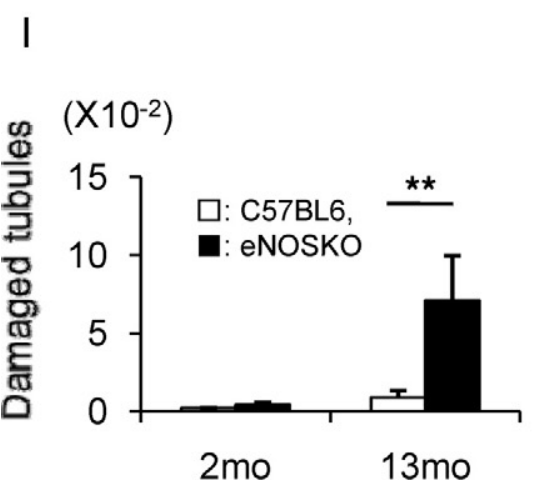

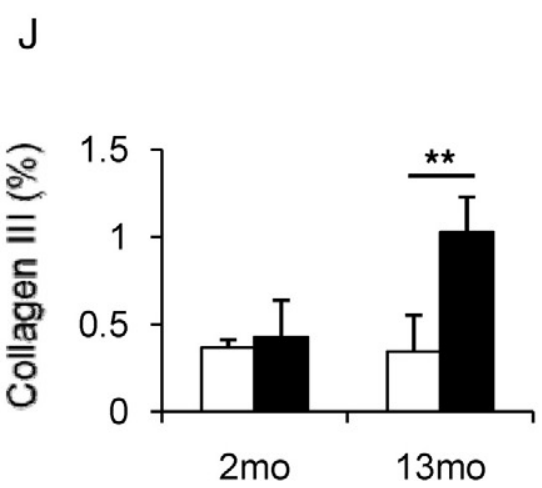

Macrophage

$\mathrm{K}$

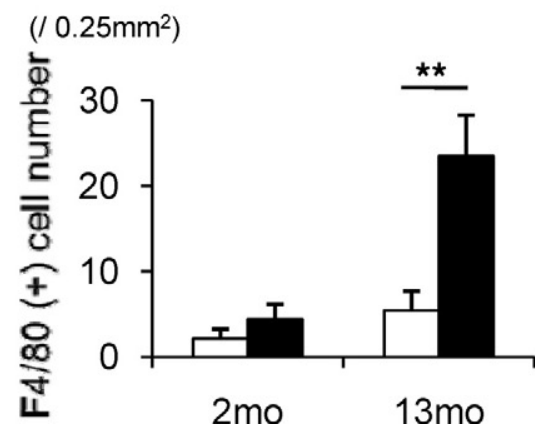

Figure 3. Tubulointerstitial injury in aging eNOSKO mice. Periodic acid-Schiff staining demonstrates appearance of normal tubulointerstitium in young eNOSKO mice (A). Compared with aging wild-type mice (B), aging eNOSKO mice exhibit tubular dilatation (arrow, C) and immune cell infiltration in the interstitium (D). Scale bar $=50 \mathrm{um}$. Immunostaining (brown color) documented increased interstitial collagen III deposition $(\mathbf{E}, \mathbf{F})$ and F4/80 $(+)$ macrophage infiltration $(\mathbf{G}, \mathbf{H})$ in aging eNOSKO mice $(\mathbf{F}, \mathbf{H})$, as compared with aging wild-type mice $(\mathbf{E}, \mathbf{G})$. Arrow indicates F 4/80 (+) macrophage. Quantitative analysis confirmed the tubular injury (I), collagen III deposition (J), and macrophage infiltration (K) in aging eNOSKO mice. White bar $=$ C57BL6; black bar $=$ eNOSKO. Data are shown as means $\pm \mathrm{SD}$. ${ }^{* *} P<0.01$.

somes in the podocyte, and vacuolation, was also detected in addition to mesangial expansion in aging eNOSKO mice by electron microscopy (Figure 2M).

\section{Tubulointerstitial Changes in Aging}

The tubulointerstitium of eNOSKO mice remained normal at 2 months of age (Figure 3A). While wild-type mice at 13 months of age showed minimal tubulointerstitial changes, eNOSKO mice at the same age had focal areas of tubulointerstitial injury with ballooning of tubules and immune cell infiltration (Figure 3, B-D). Semiquantitative analysis confirmed significant tubular damage in older (13 months old) eNOSKO mice (Figure $3 \mathrm{I}$ ). Immunohistochemistry confirmed the presence of tubulointerstitial fibrosis in aging eNOSKO mice, as evidenced by an increase in interstitial collagen III deposition and F4/80 (+) macrophage infiltration (Figure $3, \mathrm{E}-\mathrm{H}, \mathrm{J}, \mathrm{K})$.

\section{Endothelial Injury in Aging}

Since nitric oxide is one of the most important survival factors for endothelial cells, we examined if eNOS deficiency could reduce the vascular endothelium density in aging mice. As shown in Figure 4, A, B, and E, CD34 (+) endothelial cell density was identical between two groups at 2 months of age. In contrast, glomerular endothelial cells were significantly reduced in eNOSKO at 13 months old, as compared with C57BL6 mice. In contrast, no change was noted in CD34 (+) endothelial cells in peritubular capillaries in these mice (Figure 4, B-F). Compatibly, glomerular capillary density as well as absolute cap- 


\section{Endothelial staining}

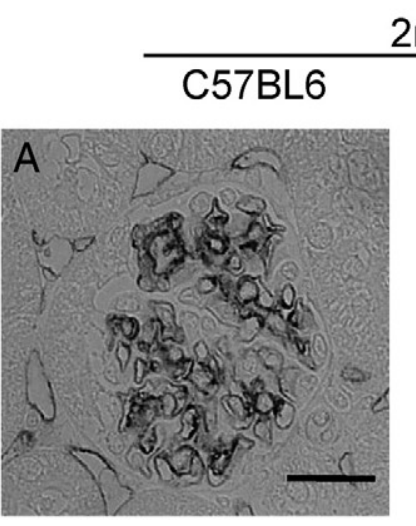

$2 \mathrm{mo}$

E

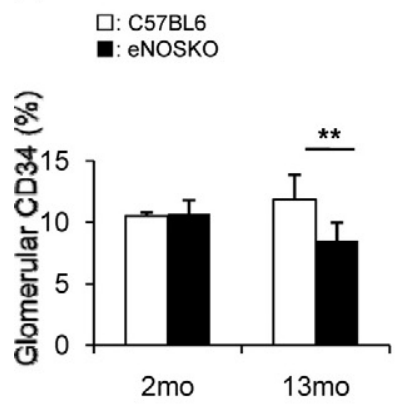

$\mathrm{F}$

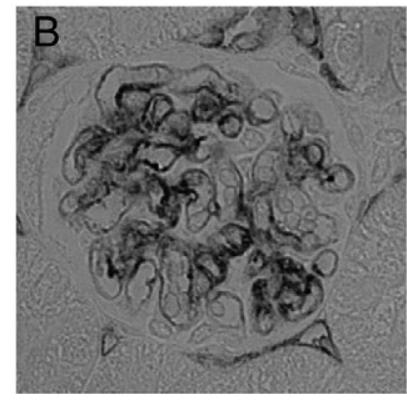

eNOSKO

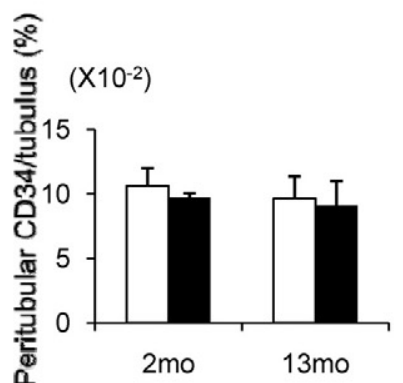

G

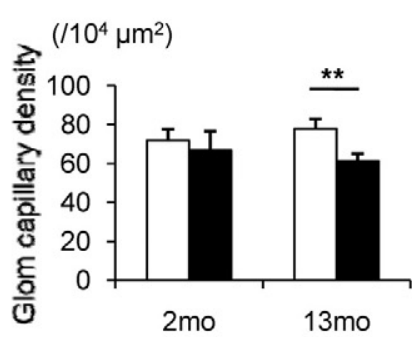

$13 \mathrm{mo}$

C57BL6 eNOSKO
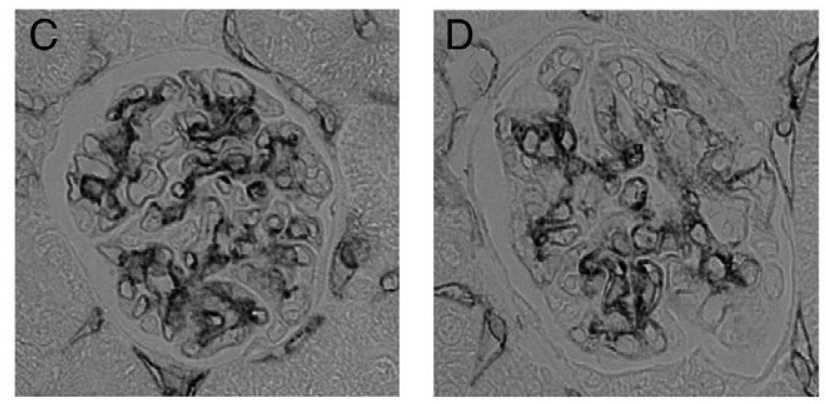

$\mathrm{H}$

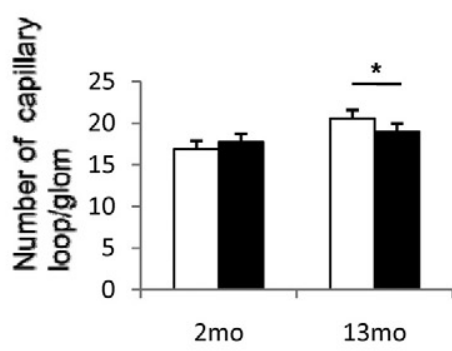

Figure 4. Endothelial injury in aging eNOSKO mice. Immunohistochemistry for CD34 positive endothelial cells (black color) demonstrates a normal appearance in wild-type (A) and eNOSKO mice (B) at 2 months of age. In contrast, at 13 months of age, CD34 (+) cells look decreased in eNOSKO mice (D), as compared with wild-type mice $(\mathbf{C})$. Quantitative analysis demonstrates that glomerular CD34 $(+)$ cell number significantly decreases in eNOSKO at 13 months of age $(\mathbf{E})$. Scale bar $=$ $20 \mu \mathrm{m}$. In contrast, CD34 (+) cell number does not decrease in peritubular capillaries $(\mathbf{F})$. Glomerular capillary density $(\mathbf{G})$, as well as capillary absolute number $(\mathbf{H})$ is also reduced in aging eNOSKO mice, as compared with that in aging wild-type mice $(\mathbf{G})$. White bar $=\mathrm{C} 57 \mathrm{BL} 6$; black bar $=$ eNOSKO. Data are shown as means \pm SD. ${ }^{*} P<0.05,{ }^{* * *} P<0.01$

illary number was also significantly reduced (Figure 4, G and $\mathrm{H})$.

\section{Fibrin Deposition in Aging eNOSKO Mice}

As shown in Figure 5, A-C, H\&E staining demonstrated that glomerular injury in aging eNOSKO mice was often associated with the accumulation of dark eosinophilic fibrillar/ amorphous material within the glomerular capillary lumens, suggesting the formation of thrombi. These thrombi often occluded the capillary lumens and occasionally contained fragmented red blood cells. Immunohistochemistry confirmed the presence of fibrinogen in the glomerular capillaries (Figure 5, D-F). Electron microscopy also confirmed that arterioles occasionally had thrombi (Figure 5, G-I). In some glomerular capillaries, the lumen was occluded due to thrombi, platelets, red cells, and endothelial cell swelling (Figure 5, G-I). By quantitative analysis, the fibrinogen deposition was significantly increased in aging eNOSKO mice compared with wild-type mice (Figure 5J). Interestingly, the fibrinogen deposition was negatively correlated with urinary nitrate/nitrite levels (Figure 5K).

\section{von Willebrand Factor in eNOSKO Mice}

The expression of $\mathrm{VWF}$ was examined in this model since VWF has a role in thrombi formation. In arterioles, inter- lobular arteries and arcuate arteries, immunostaining demonstrated that $\mathrm{VWF}$ was present in endothelial cells in eNOSKO and wild-type mice (Figure 6, A and B). In glomeruli, vWF was intensely expressed in a mesangial pattern at 2 months of age in eNOSKO mice, as compared with young wild-type mice (Figure 6, C and D). Aging eNOSKO mice had intraluminal vWF in glomerular capillaries and arterioles in addition to mesangial VWF deposition (Figure 6, E and F). To identify the location of $\checkmark W F$, we performed double staining for VWF and endothelial cells (Figure 6, G-O). The localization of vWF (red) completely overlapped with CD34 (+) endothelial cell (green), creating yellow color by merged image, in the arcuate artery of wild-type mice (Figure 6, G-I). In glomeruli of wild-type mouse, vWF showed a capillary pattern (red) which was similar to that observed with CD34 (green). Importantly, double staining confirmed that VWF was expressed by endothelial cells, as noted by the yellow color in the merged image, while some endothelial cell did not express VWF (Figure 6, J-L). In contrast, in aging eNOSKO mice the VWF distribution revealed mesangial pattern in addition to endothelial staining. Although yellow color in merged image indicates VWF expression in endothelial cells, there appears to be significant discrete red staining, which is consistent with VWF present in locations other than endothelium (Figure 6, M-O). In aging eNOSKO mice, vascular endothelial vWF was significantly 
PAS
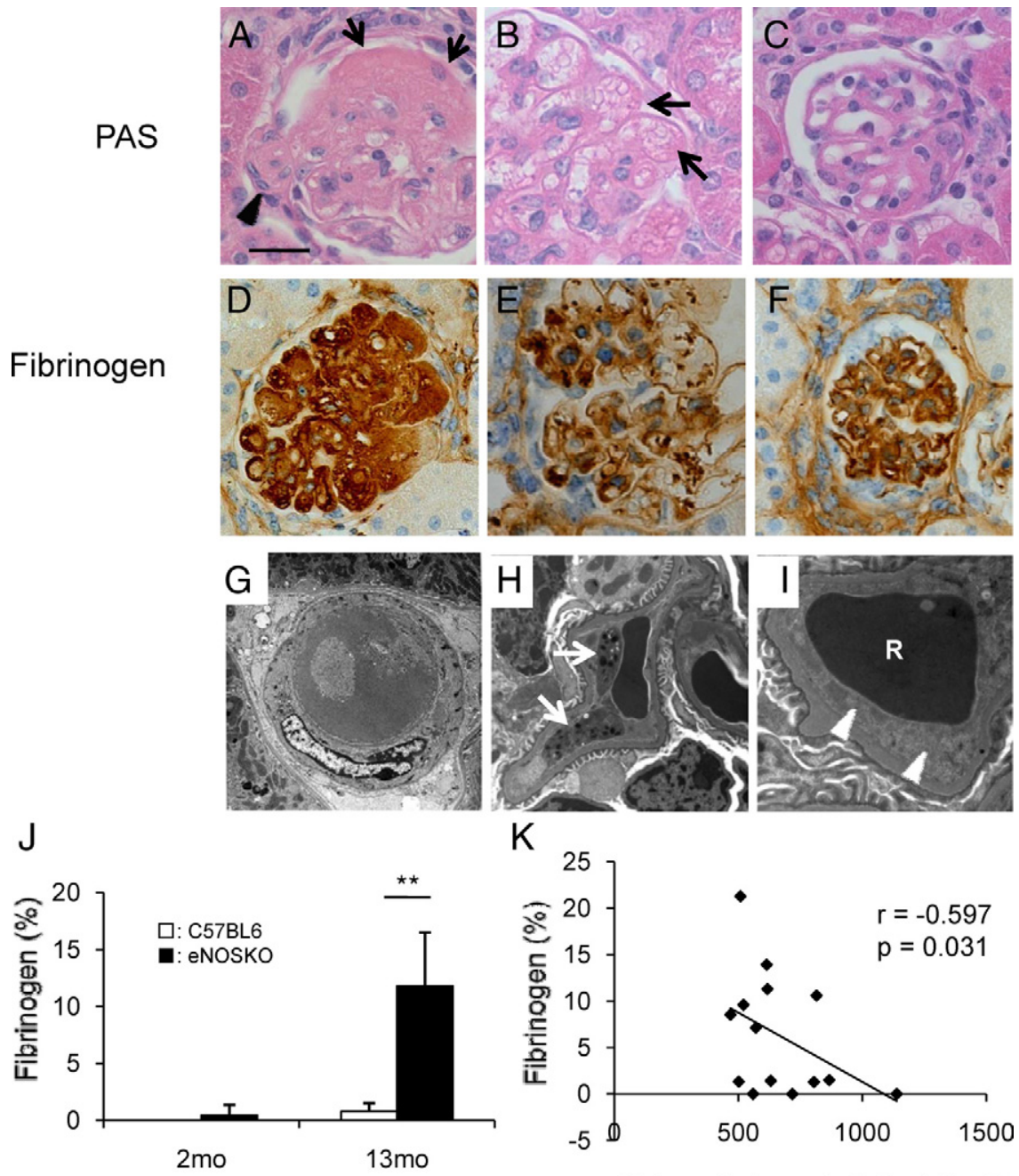

$\mathrm{K}$

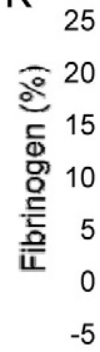

Figure 5. Thrombus formation and fibrin deposition. H\&E staining identified the presence of fibrin deposits/thrombi in glomeruli of aging eNOSKO mice (A-C). Dilated capillaries (arrow in A) and arterioles (arrowhead in A) are occasionally occluded by homogenous eosinophilic material (thrombus). Mesangiolysis was also present (B). The dilated capillary loops are congested and partially filled with fibrin (arrows in B). This glomerulus shows loss of mesangiun, microaneurysmal dilation of capillaries, and duplication of capillary walls $(\mathbf{C})$. Immunohistochemistry demonstrates the presence of fibrinogen (brown color) in occluded capillary (D) Scattered fibrinogen was seen in dilated capillary (E) and along capillary wall (F). Scale bar $=20$ $\mu \mathrm{m}$. Electron microscopy shows an arteriole, which is occluded with thrombus $(\mathbf{G}$; original magnification $\times 3000$ ). Some glomerular capillaries also contained platelets (white arrows in $\mathbf{H}$ $\times 1360000$ ), or red cell (R) trapped by swollen endothelial cells (white arrowheads) in (I; $\times 32300$ ). Quantitative analysis showed that glomerular fibrin deposition significantly increases in aging eNOSKO mice $(\mathbf{J})$. This deposition is inversely correlated with urinary nitrate and nitrite excretion $(\mathbf{K})$. White bar $=$ C57BL6; black bar $=$ eNOSKO. Data are shown as means \pm SD ${ }^{* * * *} P<0.01$. lower than that in aging wild-type mice in renal arteries and arteriole (Figure 6P). Similarly, younger mice also showed the similar pattern, while vWF level was significantly low in arcuate artery of young eNOSKO mice, as compared with age-matched wild-type mice (Figure 6P). In contrast, glomerular vWF level (in both intracapillary and mesangium) was significantly increased in eNOSKO mice. Interestingly, mesangial vWF deposition was increased in eNOSKO mice at 2 months of age, which was before glomerular injury had occurred (Figure 6Q).

Glomerular vWF expression correlated with both fibrin and type IV collagen deposition (Figure 6, R and S) and inversely with urinary nitrate/nitrite concentration (Figure $6 \mathrm{~T})$. These data are consistent with the hypothesis that vWF was released from endothelial cell in arteries of the kidney due to a lack of NO, and subsequently was deposited in the capillary and mesangium.

\section{Release of von Willebrand Factor from Weibel-Palade Bodies in Aging eNOSKO Mice}

Since both P-selectin and VWF are normally released from Weibel-Palade bodies (WPBs) present in endothelial cells into systemic circulation, serum P-selectin is often used as a surrogate marker of exocytosis of WPBs, ${ }^{13}$ and hence we examined the level of serum P-selectin in this model. In addition, the exocytosis of WPBs is also known to be induced in the absence of $\mathrm{NO} .{ }^{14}$ To confirm that exocytosis of WPBs is due to a reduction in NO, we also measured serum nitrite/nitrate levels. A lack of eNOS was associated with an increase in serum P-selectin in young eNOSKO mice, as compared with wild-type mice. Serum nitrite/nitrate level was significantly lower in young eNOSKO mice than young wild-type mice, consistent with the possibility that exocytosis of WPB could be due to lower level of NO. Interestingly, serum P-selectin was also increased in wild-type mice with aging (Figure 7A), consistent with the hypothesis that aging results in endothelial dysfunction. Compatibly, urinary nitrate/nitrite levels in aging wild-type mice were also decreased, and associated with an increase in serum P-selectin (Figure 7B). As expected, eNOSKO mice exhibited consistently low levels of urinary nitrate/nitrite level regardless of age.

\section{Discussion}

Our primary finding was that mice lacking eNOS developed accelerated renal disease with aging with a pattern consis- 
vWF staining

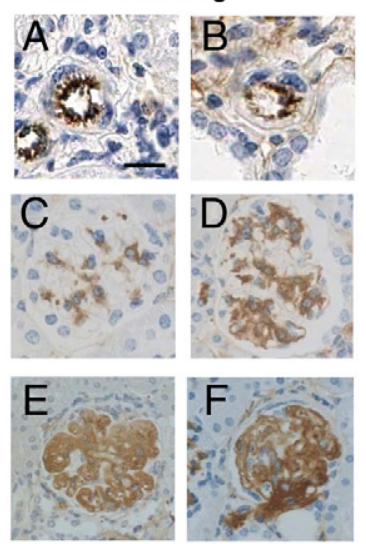

P Vascular endothelial vWF

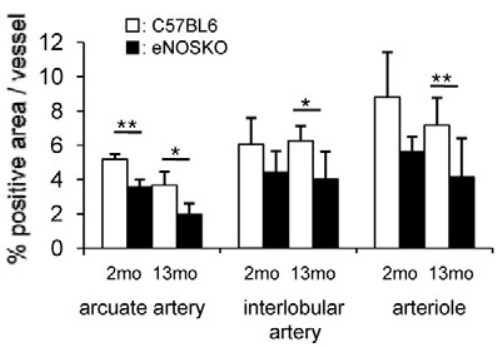

R

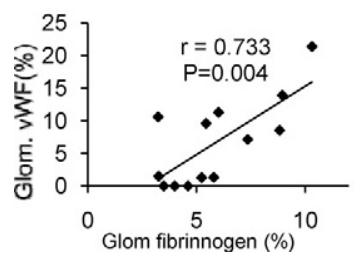

$S$

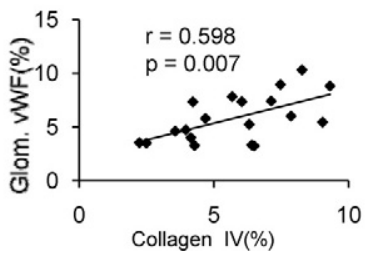

CD34
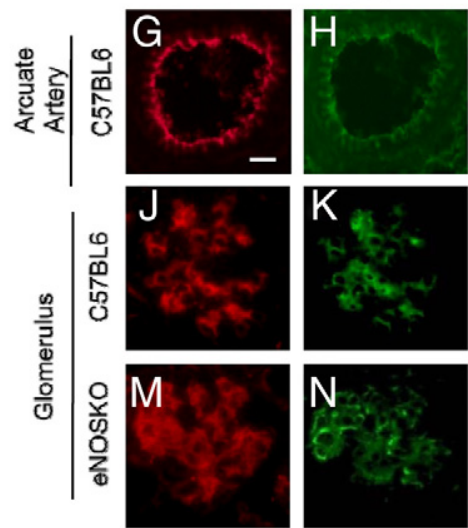

$\mathrm{N}$

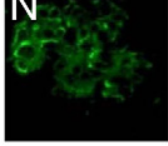

Q Glomerular vWF

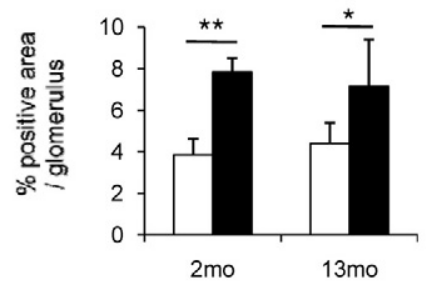

T

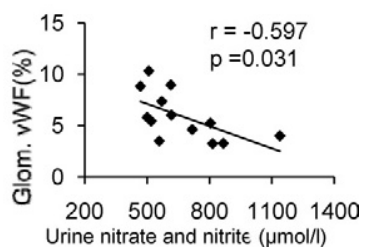

Figure 6. von Willebrand factor in aging eNOSKO mice. Immunostaining identified vWF in the endothelium in the interlobular artery in both wild-type (A) and eNOSKO (B) mice. Scale bar $=20 \mu \mathrm{m}$. Compared with young wild-type mice (C), young eNOSKO mice have a mesangial (D) vWF staining. In glomeruli of aging eNOSKO mice, vWF signal also displays intracapillary pattern in glomerular capillary $(\mathbf{E})$, as well as some arterioles (F). Double staining for vWF (red) and CD34 (green) is shown $(\mathbf{G}-\mathbf{O}$ ) The first row shows arcuate artery in the aging wild-type (C57) mouse (G-I). Location of vWF (red) (G) completely overlaps CD34 (+) endothelial cell (green) $(\mathbf{H})$, as evidenced by merged color image (yellow) (I). The second row shows glomerulus in aging wild-type (C57BL6) $(\mathbf{J}-\mathbf{L})$ Glomerular vWF (red) (J) and CD34 (green) (K) show a capillary pattern in aging wild-type mouse. Merged image (yellow) demonstrated that $\mathrm{vWF}$ is present in the endothelial cell $(\mathbf{L})$ Green color in merged image also indicates that some endothelial cell does not express vWF (L) The third row shows glomerulus in aging eNOSKO mice (M-O). In contrast to wild-type mouse, vWF (red) shows mesangial pattern (M) While CD34 (green) shows capillary pattern $(\mathbf{N})$ merged image yields both yellow and red colors $(\mathbf{O})$, indicating VWF is present not only in endothelial cell, but in other cells (probably the mesangial cell). Scale bar $=20 \mathrm{um}$. Quantification of vWF in vascular endothelial cell documented a decrease in examined vessels of eNOSKO mice compared with wild-type mice at both 2 and 13 months old whereas significant decrease is observed only in arcuate artery of young eNOSKO mice, as compared with age-matched wild-type mice $(\mathbf{P})$. In contrast, glomerular vWF significantly increases in eNOSKO mice at both 2 and 13 months old ${ }^{*} P<0.05,{ }^{* *} P<0.01(\mathbf{Q})$. Glomerular $\mathrm{vWF}$ is positively associated with fibrin (R) and collagen IV depositions (S), but negatively associated with urinary nitrate/nitrite excretion $(\mathbf{T})$. White bar $=$ C57BL6; black bar $=$ eNOSKO. Data are shown as means $\pm \mathrm{SD}$. tent with thrombotic microangiopathy. Young eNOSKO mice had minimal glomerular injury, whereas older mice subsequently developed mesangiolysis, endothelial loss, endothelial swelling, a double-contour appearance in glomerular basement membrane, and thrombi formation in glomerular capillaries and arterioles. These intracapillary thrombi were rich in fibrin, platelets, and VWF, and these findings were histologically consistent with the glomerular thrombotic microangiopathy. We also demonstrated that glomerular vWF deposition, which was documented as early as 2 months of age in eNOSKO mice, was positively associated with glomerular mesangial expansion and fibrin deposition, and negatively with urine nitrite/nitrate concen- tration. In contrast, intraluminal vWF was involved in thrombus formation in arterioles and glomerular capillary. Exocytosis of WPB was suggested as a mechanism for vWF release, since serum $\mathrm{P}$-selectin was also higher in young eNOSKO mice.

Thrombotic microangiopathy occurs in patients with hemolytic uremic syndrome and thrombotic thrombocytopenic purpura, and has been thought to be initiated by endothelial cell injury. ${ }^{15}$ Nangaku et al $^{16}$ previously developed a rat model of hemolytic uremic syndrome by administering goat anti rat-endothelial antibody. This model demonstrated that endothelial injury results in mesangiolysis, proteinuria, thrombocytopenia, and erythro-
A

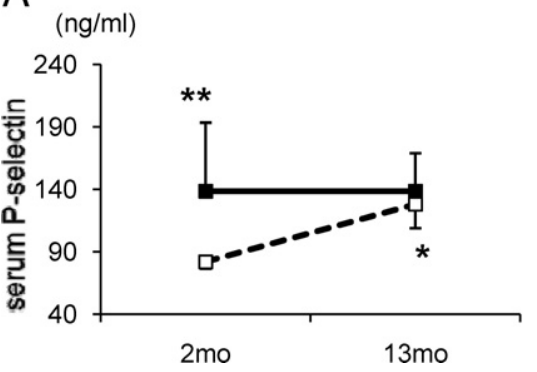

B

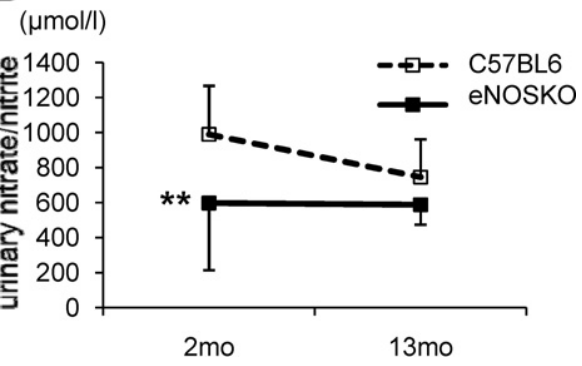

Figure 7. Exocytosis of Weibel-Palade body in aging eNOSKO mice. Serum P-selectin is significantly higher in young eNOSKO mice compared with young wild-type mice (A). Urinary nitrate and nitrite excretion is also higher in young wild-type mice compared with young eNOSKO mice $(\mathbf{B}) .{ }^{*} P<0.05$ vs. 2 Mo C57BL6 of the same age, ${ }^{* * *} P<0.01$ vs. 2 Mo C57BL6, White square $=$ C57BL6; black square $=$ eNOSKO. Data are shown as means \pm SD. 
cyte fragmentation, all of which resemble features of human thrombotic microangiopathy. Our model is of interest as the defect is limited to eNOS deficiency and a lack of endothelial NO production.

The major function of endothelial cells is to produce vasoprotective and thromboresistant molecules. Among several endothelial-derived factors, NO is known to have potent antithrombotic effects in acting on vessels, platelets, and endothelial cells. ${ }^{17,18}$ Recent studies indicate that a lack of NO causes the release of VWF from endothelial cells, ${ }^{14,19}$ where it may participate in coagulation by forming multimers and activating platelets; in addition, secreted VWF that remains anchored to the endothelial surface may facilitate platelet adhesion to injured endothelial cells. ${ }^{20}$ VWF is physiologically stored in WPB of endothelial cells and these WPB are exocytosed to release VWF in the setting of endothelial dysfunction. ${ }^{19}$ Recently, Matsushita et al $^{14}$ demonstrated, by using eNOSKO mice, that NO can negatively regulate the exocytosis of WPB. Other groups also reported that the absence of NO is correlated with increased release of WPB in iNOSKO mice. ${ }^{21}$ Given these facts, the exocytosis of WPB with release of VWF by vascular endothelial cells of the kidney may have resulted as a consequence of the lack of endothelial-derived NO in the eNOSKO mice. Our data showing an increase in serum P-selectin associated with decrease in urinary NOx excretion are also consistent with exocytosis of WPB in this model.

VWF plays an important role of microvascular thrombus formation by mediating platelet adhesion and stabilization of factor VIII. In this study, we found intracapillary VWF, but not vascular endothelial VWF, appeared to be involved in the thrombus formation in this model. In addition, we also found that the VWF deposition also occurred in mesangial regions of eNOSKO mice and interestingly, it was present even in 2-month-old mice, even when glomerular injury was minimal. Given the fact that VWF in large vessels was paradoxically reduced in eNOSKO mice, as compared with wild-type mice, it is likely that mesangial VWF could be a consequence of trapping circulating $\mathrm{VWF}^{22}$ released from endothelial cell in large vessels. In particular, mesangial vWF deposition in young eNOSKO mice could be due to its release from arcuate artery (Figure 6P). There might have other mechanisms for mesangial VWF deposition. For instance, the exudation of VWF into mesangial areas secondary to a leaky endothelium could be a cause. ${ }^{23}$ It was also reported that activated endothelial cells could secrete VWF preferentially in subendothelial areas, as opposed to in the lumen. ${ }^{24}$ Interestingly, since mesangial vWF was found to be strongly associated with glomerular collagen IV deposition, mesangial VWF could have a distinct role from thrombus formation. Endothelial dysfunction is also likely involved since glomerular VWF was negatively correlated with urinary nitrate/nitrite levels.

In terms of endothelial-podocyte interaction, the podocyte is thought to protect endothelium by expressing various factors, including vascular endothelial growth factor. ${ }^{25}$ However, in this study, we documented podocyte injury in eNOSKO mice, suggesting eNOS deficiency, in turn, leads to podocyte injury. While the precise mechanism as to how endothelial cells protect podocyte remains unclear, endothelial-derived NO could be a pivotal role to maintain podocyte function. ${ }^{26}$ Likewise, a significant loss of podocyte observed in aging wild-type mice, as compared with young wild-type mice, could be accounted for by a lower NO level (Figure 7B) or other aging associated factors. ${ }^{27}$

Aging is associated with a progressive decline in renal function and the development of glomerular and tubulointerstitial injuries. Several studies demonstrated that this aging-related renal injury is associated with the development of glomerulosclerosis, tubulointerstitial injury, and immune cell infiltration. Importantly, these injuries are also associated with glomerular and peritubular capillary loss. ${ }^{9,10}$ Our studies suggest that a lack of endothelial NO can accelerate this process, similar to what has been reported in models of glomerulonephritis, chronic kidney disease, and diabetic nephropathy. $3,5,6$ We further show that a lack of endothelial NO results in a pattern of injury that resembles thrombotic microangiopathy. Thus, these studies document the importance of a healthy endothelium in preventing aging-associated kidney disease in the mouse.

\section{Acknowledgments}

We thank Mr. Norihiko Suzuki (Nagoya University, Nagoya, Japan) for excellent technical assistance and Dr. Richard J. Johnson (University of Colorado, Denver) for precious advice and critical review of this manuscript.

\section{References}

1. Huang PL, Huang Z, Mashimo H, Bloch KD, Moskowitz MA, Bevan JA, Fishman MC: Hypertension in mice lacking the gene for endothelial nitric oxide synthase. Nature 1995, 377:239-242

2. Forbes MS, Thornhill BA, Park MH, Chevalier RL: Lack of endothelial nitric-oxide synthase leads to progressive focal renal injury. Am J Pathol 2007, 170:87-99

3. Heeringa $P$, van Goor $H$, Itoh-Lindstrom $Y$, Maeda N, Falk RJ, Assmann KJ, Kallenberg CG, Jennette JC: Lack of endothelial nitric oxide synthase aggravates murine accelerated anti-glomerular basement membrane glomerulonephritis. Am J Pathol 2000, 156:879-888

4. Shesely EG, Maeda N, Kim HS, Desai KM, Krege JH, Laubach VE, Sherman PA, Sessa WC, Smithies O: Elevated blood pressures in mice lacking endothelial nitric oxide synthase. Proc Natl Acad Sci USA 1996, 93:13176-13181

5. Nakagawa T, Sato W, Glushakova O, Heinig M, Clarke T, CampbellThompson M, Yuzawa Y, Atkinson M, Johnson RJ, Croker B: Diabetic eNOS knockout mice develop advanced diabetic nephropathy. J Am Soc Nephrol 2007, 18:539-550

6. Nakayama T, Sato W, Kosugi T, Zhang L, Campbell-Thompson M, Yoshimura A, Croker BP, Johnson RJ, Nakagawa T: Endothelial injury due to eNOS deficiency accelerates the progression of chronic renal disease in the mouse. Am J Physiol Renal Physiol 2008, 296:317-327

7. Mendoza MG, Castillo-Henkel C, Medina-Santillan R, Jarillo Luna RA, Robles HV, Romo E, Rios A, Escalante B: Kidney damage after renal ablation is worsened in endothelial nitric oxide synthase - /- mice and improved by combined administration of L-arginine and antioxidants. Nephrology (Carlton) 2008, 13:218-227

8. Yamashita C, Tazawa N, Ohkita M, Matsumura Y: Exaggerated renal pathology of partial ablation-induced chronic renal failure in eNOS deficient mice. Biol Pharm Bull 2008, 31:1029-1031

9. Kang DH, Anderson S, Kim YG, Mazzalli M, Suga S, Jefferson JA, Gordon KL, Oyama TT, Hughes J, Hugo C, Kerjaschki D, Schreiner 
GF, Johnson RJ: Impaired angiogenesis in the aging kidney: vascular endothelial growth factor and thrombospondin-1 in renal disease. Am J Kidney Dis 2001, 37:601-611

10. Thomas SE, Anderson S, Gordon KL, Oyama TT, Shankland SJ, Johnson RJ: Tubulointerstitial disease in aging: evidence for underlying peritubular capillary damage, a potential role for renal ischemia. J Am Soc Nephrol 1998, 9:231-242

11. Hayashi T, Matsui-Hirai H, Miyazaki-Akita A, Fukatsu A, Funami J, Ding QF, Kamalanathan S, Hattori Y, Ignarro LJ, Iguchi A: Endothelial cellular senescence is inhibited by nitric oxide: implications in atherosclerosis associated with menopause and diabetes. Proc Natl Acad Sci USA 2006, 103:17018-17023

12. Bergstein JM: Tissue plasminogen activator therapy of glomerular thrombi in the Shwartzman reaction. Kidney Int 1989, 35:14-18

13. Kuo MC, Patschan D, Patschan S, Cohen-Gould L, Park HC, Ni J, Addabbo F, Goligorsky MS: Ischemia-induced exocytosis of WeibelPalade bodies mobilizes stem cells. J Am Soc Nephrol 2008, 19:23212330

14. Matsushita K, Morrell CN, Cambien B, Yang SX, Yamakuchi M, Bao C, Hara MR, Quick RA, Cao W, O'Rourke B, Lowenstein JM, Pevsner J, Wagner DD, Lowenstein CJ: Nitric oxide regulates exocytosis by S-nitrosylation of $\mathrm{N}$-ethylmaleimide-sensitive factor. Cell 2003, 115:139-150

15. Ruggenenti P, Noris M, Remuzzi G: Thrombotic microangiopathy, hemolytic uremic syndrome, and thrombotic thrombocytopenic purpura. Kidney Int 2001, 60:831-846

16. Nangaku M, Alpers CE, Pippin J, Shankland SJ, Adler S, Kurokawa K, Couser WG, Johnson RJ: A new model of renal microvascular endothelial injury. Kidney Int 1997, 52:182-194

17. Wu KK, Thiagarajan P: Role of endothelium in thrombosis and hemostasis. Annu Rev Med 1996, 47:315-331

18. Tsai HM: The molecular biology of thrombotic microangiopathy. Kidney Int 2006, 70:16-23
19. Lowenstein CJ, Morrell CN, Yamakuchi M: Regulation of WeibelPalade body exocytosis. Trends Cardiovasc Med 2005, 15:302-308

20. Dong JF, Moake JL, Nolasco L, Bernardo A, Arceneaux W, Shrimpton CN, Schade AJ, McIntire LV, Fujikawa K, Lopez JA: ADAMTS-13 rapidly cleaves newly secreted ultralarge von Willebrand factor multimers on the endothelial surface under flowing conditions. Blood 2002, 100:4033-4039

21. Qian Z, Gelzer-Bell R, Yang Sx SX, Cao W, Ohnishi T, Wasowska BA Hruban RH, Rodriguez ER, Baldwin WM, 3rd, Lowenstein CJ: Inducible nitric oxide synthase inhibition of Weibel-Palade body release in cardiac transplant rejection. Circulation 2001, 104:2369-2375

22. Michael AF, Keane WF, Raij L, Vernier RL, Mauer SM: The glomerular mesangium. Kidney Int 1980, 17:141-154

23. Lagoo AS, Buckley PJ, Burchell LJ, Peters D, Fechner JH, Tsuchida M, Dong Y, Hong X, Brunner KG, Oberley TD, Hamawy MM, Knechtle SJ: Increased glomerular deposits of von Willebrand factor in chronic, but not acute, rejection of primate renal allografts. Transplantation 2000, 70:877-886

24. van Buul-Wortelboer MF, Brinkman HJ, Reinders JH, van Aken WG, van Mourik JA: Polar secretion of von Willebrand factor by endothelial cells. Biochim Biophys Acta 1989, 1011:129-133

25. Eremina V, Sood M, Haigh J, Nagy A, Lajoie G, Ferrara N, Gerber HP, Kikkawa Y, Miner JH, Quaggin SE: Glomerular-specific alterations of VEGF-A expression lead to distinct congenital and acquired renal diseases. J Clin Invest 2003, 111:707-716

26. Lewko B, Stepinski J: Cyclic GMP signaling in podocytes. Microsc Res Tech 2002, 57:232-235

27. Sanden SK, Wiggins JE, Goyal M, Riggs LK, Wiggins RC: Evaluation of a thick and thin section method for estimation of podocyte number, glomerular volume, and glomerular volume per podocyte in rat kidney with Wilms' tumor-1 protein used as a podocyte nuclear marker. J Am Soc Nephrol 2003, 14:2484-2493 